\title{
Fostering knowledge sharing behaviour among public sector managers: a proposed model for the Malaysian public service
}

\begin{abstract}
Purpose: This paper aims to propose a conceptual model of knowledge sharing behaviour among Malaysian public sector managers. Design/methodology/approach: An extensive literature review method was used to identify and analyse relevant literature in order to propose a knowledge sharing model. Findings: The authors identified three potential predictor groups of knowledge sharing behaviour among Malaysian public sector managers. The groups are intrinsic motivational factors, extrinsic motivational factors and organisational socialisation factors. The paper proposes organisational commitment as the mediating variable between the identified predictors and knowledge sharing behaviour (knowledge donating and knowledge collecting). Research limitations/implications: The paper offers a number of propositions, which leads to a knowledge sharing model. Future research should validate and examine the predictive power of the proposed model. Practical implications: Upon model validation, the paper could offer practical interventions for human resource development (HRD) practitioners to assist organisations towards fostering knowledge sharing behaviour. The paper highlights the importance of employee's organisational commitment in order to engage in organizational-related behaviours such as knowledge sharing. Originality/value: The paper used a new approach in theorising knowledge sharing behaviour by integrating the General Workplace Commitment Model, Self-Determination Theory and Social Capital Theory. The suggestion of public service motivation as one of the intrinsic motivational factors could provide new insights to the HRD practitioners on fostering knowledge sharing behaviour in the public service subject to model validation.
\end{abstract}

Keyword: Public sector; Knowledge management; Knowledge sharing; Managers;

Knowledge collecting; Knowledge donating 